\title{
Regression of Colonic Adenomas After Treatment With Sulindac in Familial Adenomatous Polyposis: A Case With a 2-Year Follow-up Without a Prophylactic Colectomy
}

\author{
Kyu Young Kim, Seong Woo Jeon, Jung Gil Park, Chung Hoon Yu, Se Young Jang, Jae Kwang Lee, \\ Hee Young Hwang \\ Department of Internal Medicine, Kyungpook National University School of Medicine, Daegu, Korea
}

Familial adenomatous polyposis (FAP) is an autosomal dominant disorder characterized by hundreds of colorectal adenomatous polyps that progress to colorectal cancer. Management of patients with FAP is with a total colectomy. Chemopreventive strategies have been studied in FAP patients in an effort to delay the development of adenomas in the upper and the lower gastrointestinal tract and to prevent recurrence of adenomas in the retained rectum of patients after prophylactic surgery. Sulindac, a nonsteroidal anti-inflammatory drug, causes regression of colorectal adenomas in the retained rectal segment of FAP patients. However, evidence regarding long-term use of this therapy and its effect on the intact colon has been insufficient. We report a case in which the long-term use of sulindac was effective in reducing the size and the number of colonic polyps in patients with FAP without a prophylactic colectomy and polypectomy; we also present a review of the literature.

Keywords: Adenomatous polyposis coli; Sulindac; Therapy; Chemoprevention

\section{INTRODUCTION}

Familial adenomatous polyposis (FAP) is an autosomal dominant disease caused by a mutation in the adenomatous polyposis coli $(A P C)$ gene located on chromosome $5 q 21$ [1]. This mutation accelerates the initiation of the adenoma-carcinoma sequence, resulting in the development of numerous adenomatous colorectal polyps at a young age. Polyposis will inevitably progress to colorectal cancer if a prophylactic colectomy is not performed. Given the predictability of the development of colorectal cancer in patients

Received: January 12,2014 • Accepted: February 11, 2014

Correspondence to: Seong Woo Jeon, M.D.

Department of Internal Medicine, Kyungpook National University Medical Center, Kyungpook National University School of Medicine,

130 Dongdeok-ro, Jung-gu, Daegu 700-721, Korea

Tel: +82-53-420-5512, Fax: +82-53-426-8773

E-mail:sw-jeon@daum.net

(C) 2014 The Korean Society of Coloproctology

This is an open-access article distributed under the terms of the Creative Commons Attribution NonCommercial License (http://creativecommons.org/licenses/by-nc/3.0) which permits unrestricted noncommercial use, distribution, and reproduction in any medium, provided the original work is properly cited. with FAP, the safest preventative strategy is surgical resection of the colon when polyposis develops [2]. In 1983, Waddell and Loughry [3] were the first to report sulindac-induced regression of adenomas in patients who underwent a colectomy with ileorectal anastomosis (IRA). However, evidence regarding long-term use of this therapy and its effect on the intact colon is insufficient [4]. In the present study, we report a case of FAP, in which the patient took sulindac without surgery or a polypectomy and showed regression of the colonic adenomas for more than 2 years.

\section{CASE REPORT}

A 25-year-old woman visited Department of Internal Medicine, Kyungpook National University Medical Center due to multiple colon polyps that had been detected incidentally. She had been healthy and had no remarkable medical history. According to her family history, her mother had colon cancer, and her brother had undergone a prophylactic colectomy for the treatment of FAP. The results of physical examination and laboratory data, including complete blood count and serum carcinoembryonic antigen level, were all within normal limits. Esophagogastroduodenos- 


\section{Coloproctology Kyu Young Kim, et al.}

copy showed a normal mucosa finding. Colonoscopy examination revealed hundreds of polyps carpeting the entire colon and rectum, consistent with FAP (Fig. 1). Histologically, these polyps were all proven to be tubular adenomas. Because the standard therapy is a prophylactic total colectomy, we recommended that she undergo a prophylactic surgical treatment. However, the patient was fully aware of the unfavorable effect that a total colectomy had had on her brother. In addition, she was 25 and single.

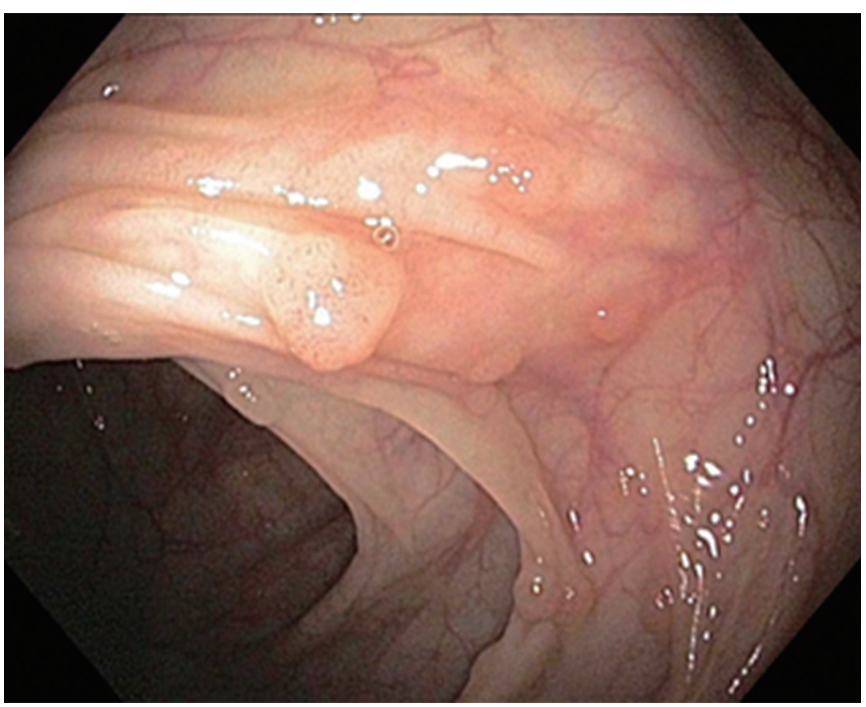

Fig. 1. Colonoscopy showed hundreds of polyps of various sizes carpeting the entire colon and rectum, which is consistent with familial adenomatous polyposis.

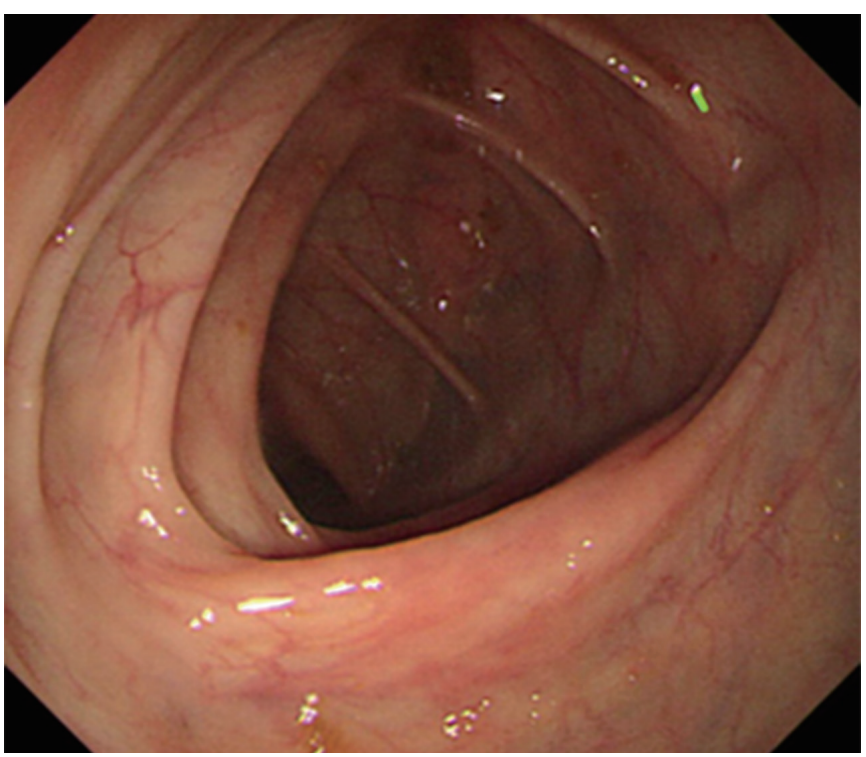

Fig. 2. After sulindac medication had been taken for 5 months, colonoscopy showed that the number and the size of polyps had been drastically decreased and that the polyps had almost completely disappeared.
She had no large-sized polyps and no colon cancer. Her family agreed with our second proposal, which was not to perform surgical treatment until the subject was in her late twenties, if there was no apparent development of colonic cancer. Therefore, we delayed the prophylactic colectomy and decided on a treatment with oral sulindac, $100 \mathrm{mg}$ twice a day.

After the sulindac medication had been taken for 5 months, colonoscopy showed that the number and the size of polyps had been drastically decreased and that the polyps had almost completely disappeared (Fig. 2). Sulindac was found to have a sustained effect on the complete regression of colonic adenomas without the need for a polypectomy. Mild nausea was a side effect of the medication. However, after a few days, symptoms had disappeared without treatment. After the sulindac medication had been taken for 25 months, colonoscopy showed several sporadic, tiny polyps (Fig. 3). Thus, the effect of sulindac on the regression of the colonic adenomas had been maintained. We had been continuously treating her with oral sulindac, $100 \mathrm{mg}$ twice a day. Esophagogastroduodenoscopy and colonoscopy were scheduled at regular intervals of one year.

\section{DISCUSSION}

Cancer prevention and maintenance of a good quality of life are the main goals in management of patients with clinical or genetic evidence of FAP. The two main options for prophylactic removal of the large intestine are a colectomy with IRA and a proctocolectomy with ileal pouch-anal anastomosis [2]. Chemoprevention is the use of pharmaceuticals or natural agents to prevent or delay the development of cancer in healthy patients. Ideally, the agents

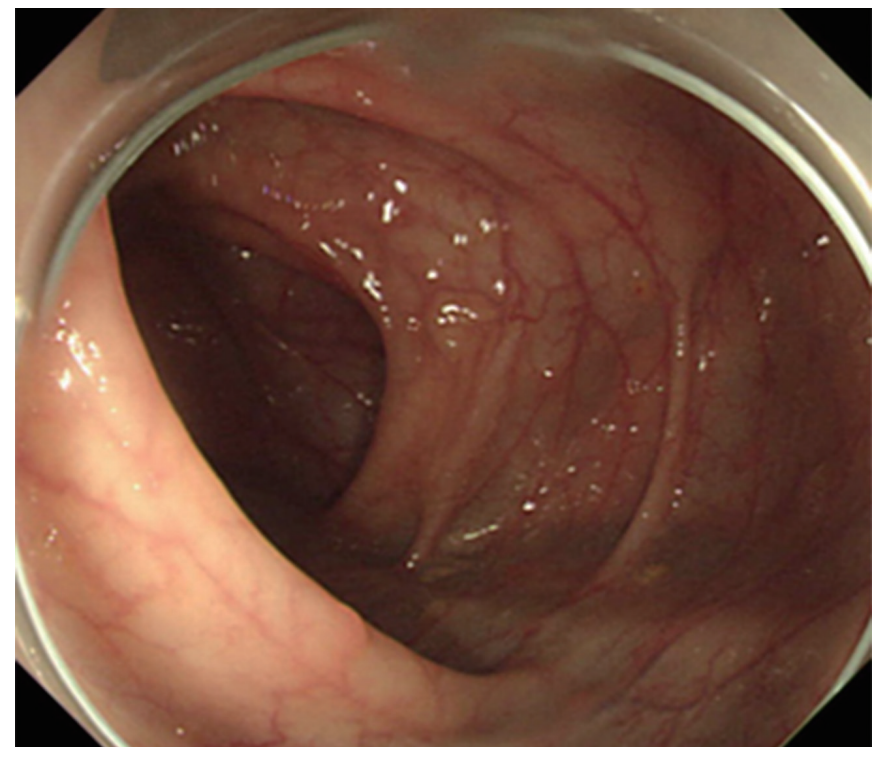

Fig. 3. After sulindac medication had been taken for 25 months, colonoscopy showed several, sporadic, tiny polyps. 
used in chemoprevention should be well tolerated, low in toxicity, cheap, and effective. Chemoprevention can play three main roles in patients with FAP: (1) delay of the prophylactic colectomy, (2) prevention of cancer development in the retained rectum in patients after a colectomy with IRA, and (3) prevention of cancer development in the upper gastrointestinal tract, especially the duodenum [5].

Sulindac is a nonsteroidal anti-inflammatory drug (NSAID) that inhibits prostaglandin synthesis. NSAIDs have been studied extensively as chemopreventive agents in patients with FAP. NSAIDs (including sulindac) inhibit cyclooxygenase (COX), a key enzyme in the conversion of arachidonic acid to prostaglandins and other eicosanoids. Prostaglandins appear to play a key role in the adenoma-carcinoma sequence by altering cell adhesion, inhibiting apoptosis, and promoting angiogenesis. Elevated prostaglandin levels are found in many premalignant and malignant lesions, including colorectal adenomas and adenocarcinomas. Sulindac reduces prostaglandin synthesis by inhibiting the expressions of the COX-1 and the COX-2 enzymes [5].

In this case, we administered sulindac for more than 2 years. Regression of the colonic adenomas occurred 5 months after the start of treatment and has continued for more than 20 months since that time. In 1983, Waddell and Loughry [3] reported that sulindac, a NSAID, caused regression of rectal adenomatous polyps in patients with FAP. One patient had diffuse polyposis in an intact colon. In their case, after sulindac therapy for one year, only three small mucosal polyps could be identified by colonoscopy.

The effect of sulindac was confirmed in randomized, doubleblind, placebo-controlled studies (Table 1) [6-8]. One study [6] showed a significant decrease in the number and the size of polyps in the intact colon of 18 patients. However, in all studies, the rate of complete resolution during a treatment period shorter than one year was not so high, and the effect of sulindac proved to be transient and reversible. Several nonrandomized clinical trials have verified the chemoprevention effect of sulindac in FAP patients (Table 2) [9-12]. Two studies [10,11] showed apparent effects on the regression of adenomas in the intact colon.

However, in other studies, whether the effect of sulindac in preventing polyps also applies to carcinomas is not clear. The persistence of an abnormal mucosal proliferation after sulindac therapy, in spite of a reduction in the number of polyps, suggests that caution is needed in assuming a lower risk of rectal cancer in patients with FAP [11]. Accordingly, the longer the period of treatment with sulindac is, the more intensive the surveillance that is necessary. Moreover, two studies have been done on the development of colorectal adenocarcinomas during sulindac therapy with polyp regression. One study [13] reported a patient with FAP who developed a second primary carcinoma in a remnant rectal segment after a colectomy with IRA during sulindac treatment. Despite intensive endoscopic follow-up, the patient developed an adenocarcinoma of the rectum 28 months after the colectomy. This finding may have important implications for our understanding of the development of colon cancer in patients with FAP and the use of sulindac to prevent it. Development of de novo carcinoma in microadenomatous tissue of the rectal mucosa, which bypasses the polyp-cancer sequence, must be considered as a possibility in these patients. The other study [14] reported a patient with FAP in whom a rectal adenocarcinoma developed 15 months after be-

Table 1. Randomized, placebo-controlled, clinical trials of sulindac chemoprevention in familial adenomatous polyposis patients

\begin{tabular}{|c|c|c|c|}
\hline Ref. no. & Patients' characteristic & Duration (mo) & Outcome \\
\hline 6 & $\begin{array}{l}\text { Total } 22 \text { patients } \\
\text { Eighteen patients had intact colons }\end{array}$ & 9 & $\begin{array}{l}\text { At } 9 \text { months, the sulindac group had a decrease in the number of polyps by } 56 \%(P=0.014) \\
\text { and a decrease in the size of the polyps by } 65 \%(P<0.001)\end{array}$ \\
\hline 7 & $\begin{array}{l}\text { Total } 9 \text { patients } \\
\text { All patients had a previous colectomy with IRA }\end{array}$ & 4 & $\begin{array}{l}\text { Statistically significant decrease in rectal polyps in sulindac vs. placebo }(P<0.01) \\
\text { Recurrence of polyps after discontinuation of sulindac }\end{array}$ \\
\hline 8 & $\begin{array}{l}\text { Total } 24 \text { patients } \\
\text { All patients had a previous colectomy with IRA }\end{array}$ & 6 & Rectal polyps improved in five of seven patients $(P=0.01)$ taking sulindac \\
\hline
\end{tabular}

IRA, ileorectal anastomosis.

Table 2. Nonrandomized, clinical trials of sulindac chemoprevention in familial adenomatous polyposis patients

\begin{tabular}{clcc}
\hline Ref. no. & \multicolumn{1}{c}{ Patients' characteristic } & Duration & \multicolumn{1}{c}{ Outcome } \\
\hline 9 & Total 12 patients & $14-98$ & At 12 months, a 74\% reduction in the number of polyps $(P=0.02)$ and a significant \\
& All patients had a previous colectomy with IRA & Months & reduction in high-grade adenomas $(P=0.004)$ were noted \\
10 & Total 10 patients & $12-85$ & Decrease in the number of polyps in all patients \\
& Four patients had intact colons & Months & \\
11 & Total 20 patients & 60 & Dramatic decrease in the size and the number of polyps $(P<0.001)$ \\
& Six patients had intact colons & Days & \\
12 & Total 28 patients & $3-48$ & All patients had a reduction in polyposis at 24 weeks \\
& All patients had a previous colectomy with IRA & Months & \\
\hline
\end{tabular}

IRA, ileorectal anastomosis. 
ginning chemoprevention with sulindac. The carcinoma was a metastatic adenocarcinoma in 6 of 20 perirectal lymph nodes, although an endoscopic examination performed 3 months before had been unremarkable. In addition to the carcinoma, the rectal mucosa contained two adenomas and multiple foci of adenomatous changes in the flat mucosa. This study concluded that sulindac may not alter the pathogenesis of FAP. The authors recommended that patients undergoing sulindac chemoprevention be monitored closely, including endoscopic examination with an aggressive biopsy approach, because the absence of polyps does not prove the absence of neoplastic change.

Giardiello et al. [15] reported that sulindac's potential as a primary chemopreventive agent in patients with FAP. Forty-one patients with APC mutations, who were genotypically affected, but were not yet phenotypically affected, were randomized into a group that received a placebo and a group that received sulindac as a primary prophylaxis against the development of colorectal adenomas. After four years of treatment, no significant differences between the two groups were seen. Adenomas had developed in 9 of 21 patients receiving sulindac (43\%) and in 11 of 20 patients receiving the placebo $(55 \%, \mathrm{P}=0.54)$. No significant differences in the mean numbers of polyps and in the sizes of the polyps were noted between the two groups. This result provided no support for the use of NSAIDs such as sulindac for the primary treatment of FAP. The prophylactic colectomy remains the treatment of choice to prevent colorectal cancer in patients with FAP [15].

In conclusion, sulindac cannot replace a prophylactic total colectomy as the primary therapy for treating patients with FAP. However, sulindac therapy may be useful for postponing the total colectomy, especially for a young person who refuses prophylactic surgery or for attenuated FAP.

\section{CONFLICT OF INTEREST}

No potential conflict of interest relevant to this article was reported.

\section{REFERENCES}

1. Kinzler KW, Nilbert MC, Su LK, Vogelstein B, Bryan TM, Levy $\mathrm{DB}$, et al. Identification of FAP locus genes from chromosome 5q21. Science 1991;253:661-5.
2. Vasen HF, Moslein G, Alonso A, Aretz S, Bernstein I, Bertario L, et al. Guidelines for the clinical management of familial adenomatous polyposis (FAP). Gut 2008;57:704-13.

3. Waddell WR, Loughry RW. Sulindac for polyposis of the colon. J Surg Oncol 1983;24:83-7.

4. Tonelli F, Valanzano R, Messerini L, Ficari F. Long-term treatment with sulindac in familial adenomatous polyposis: is there an actual efficacy in prevention of rectal cancer? J Surg Oncol 2000;74: 15-20.

5. Kim B, Giardiello FM. Chemoprevention in familial adenomatous polyposis. Best Pract Res Clin Gastroenterol 2011;25:607-22.

6. Giardiello FM, Hamilton SR, Krush AJ, Piantadosi S, Hylind LM, Celano P, et al. Treatment of colonic and rectal adenomas with sulindac in familial adenomatous polyposis. N Engl J Med 1993; 328:1313-6.

7. Labayle D, Fischer D, Vielh P, Drouhin F, Pariente A, Bories C, et al. Sulindac causes regression of rectal polyps in familial adenomatous polyposis. Gastroenterology 1991;101:635-9.

8. Nugent KP, Farmer KC, Spigelman AD, Williams CB, Phillips RK. Randomized controlled trial of the effect of sulindac on duodenal and rectal polyposis and cell proliferation in patients with familial adenomatous polyposis. Br J Surg 1993;80:1618-9.

9. Cruz-Correa M, Hylind LM, Romans KE, Booker SV, Giardiello FM. Long-term treatment with sulindac in familial adenomatous polyposis: a prospective cohort study. Gastroenterology 2002;122: 641-5.

10. Waddell WR, Ganser GF, Cerise EJ, Loughry RW. Sulindac for polyposis of the colon. Am J Surg 1989;157:175-9.

11. Spagnesi MT, Tonelli F, Dolara P, Caderni G, Valanzano R, Anastasi A, et al. Rectal proliferation and polyp occurrence in patients with familial adenomatous polyposis after sulindac treatment. Gastroenterology 1994;106:362-6.

12. Winde G, Schmid KW, Brandt B, Muller O, Osswald H. Clinical and genomic influence of sulindac on rectal mucosa in familial adenomatous polyposis. Dis Colon Rectum 1997;40:1156-68.

13. Niv Y, Fraser GM. Adenocarcinoma in the rectal segment in familial polyposis coli is not prevented by sulindac therapy. Gastroenterology 1994;107:854-7.

14. Lynch HT, Thorson AG, Smyrk T. Rectal cancer after prolonged sulindac chemoprevention: a case report. Cancer 1995;75:936-8.

15. Giardiello FM, Yang VW, Hylind LM, Krush AJ, Petersen GM, Trimbath JD, et al. Primary chemoprevention of familial adenomatous polyposis with sulindac. N Engl J Med 2002;346:1054-9. 